\title{
Schedule-control of behavior in squirrel monkeys: Effects of methylphenidate'
}

\section{R. STRETCH AND N. SKINHER}

UNIVERSITY OF ALBERTA

Methylphenidate differentially affected response rates maintained by fixed-interval and fixed-ratio schedules of reinforcement involving termination of conditioned aversive stimulation. Results support and extend a suggestion that the schedule per se may be a more important determinant of drug-behavior dependencies than the nature of the reinforcer used in behavioral control.

Characteristics of behavior, differentially sensitive to the effects of drugs, can be generated by employing different schedules of reinforcement or by changing schedule parameters (Dews \& Morse, 1961; Gollub \& Brady, 1965). Since drugs that exert central excitatory effects (e.g., the amphetamines) generally increase rates of operant responding under schedules that engender low rates and decrease the output of responses under schedules yielding higher rates, Dews (1958a, b) suggested that their behavioral effects are determined largely by the frequency of occurrence of the response being studied. Present observations confirm Dews' proposal in a situation in which response rates, reinforced intermittently by termination of conditioned aversive stimuli (CAS), were maintained.

Method

Two male squirrel monkeys (Saimiri sciureus), designated W2 and W3, served as Ss. Both were first trained to press a lever to terminate, simultaneously, noise (78 dB) and a white light previously associated with shock delivered through the grid floor of a standard conditioning chamber. Subsequently, the following conditions were established over four months: W2 was required to make 250 responses (FR 250) to terminate noise and light for a $3 \mathrm{~min}$ period during which time the response lever was retracted. If W2 failed to meet the FR requirement within $180 \mathrm{sec}$ timed from noise-light onset, a $0.5 \mathrm{sec}(12 \mathrm{~mA})$ shock was delivered and repeated at 3 min intervals until the completion of the FR. W3 was trained on a fixed interval of $3 \mathrm{~min}$ (FI 3), i.e., after noise-light onset, responses were ineffective in terminating these stimuli until $180 \mathrm{sec}$ elapsed; the first response occurring after $180 \mathrm{sec}$ terminated noise and light for $3 \mathrm{~min}$, a period which was accompanied by lever retraction. If $W 3$ failed to make a response within $2 \mathrm{sec}$ of the end of the FI, a $0.5 \mathrm{sec}$ shock occurred and was repeated every $2 \mathrm{sec}$ until a response was made.

Daily experimental sessions lasted $225 \mathrm{~min}$. After 30-35 further sessions under the final parameters had been given to ensure stability of control performances, methylphenidate at dosages of 1,2 , and $4 \mathrm{mg} / \mathrm{kg}$ was injected IP a minute before commencement of a daily session; five determinations of the effects of each dos- age were obtained on separate occasions interspersed with control sessions.

\section{Results and Discussion}

Cumulative response records (Fig. 1) show typical control performances for W3 (A) and W2 (C) and illustrate the main differences in rate and temporal distribution of responding observed under the FT and FR schedules of CAS termination. The FI schedule (A) produced a lower overall rate than the FR, which consisted of a pause at the beginning of the interval followed, once responding had begun, by a steadily increasing rate until the end of the interval; the increasing rate yielded curvature within the record resembling the pattern of responding obtained with an FI schedule of food reinforcement. FR 250 (C) produced a higher and more uniform overall rate than FI which followed an initial pause after the onset of CAS and was continued until reinforcement occurred. In spite of some procedural differences, the data are consistent with those reported previously (Morse \& Kelleher, 1966) and confirm the view that behavior maintained by these schedules resembles closely FI and FR patterns of responding controlled by food reinforcement.

Figure 2A shows that methylphenidate affected FI and FR response rates differentially. Rate-decreasing effects of the drug were observed during the first $45 \mathrm{~min}$ after injection as an increasing function of dosage when responding was maintained by FR 250 , but rate changes were less pronounced relative to the changes produced by the drug when administered to W3. Methylphenidate

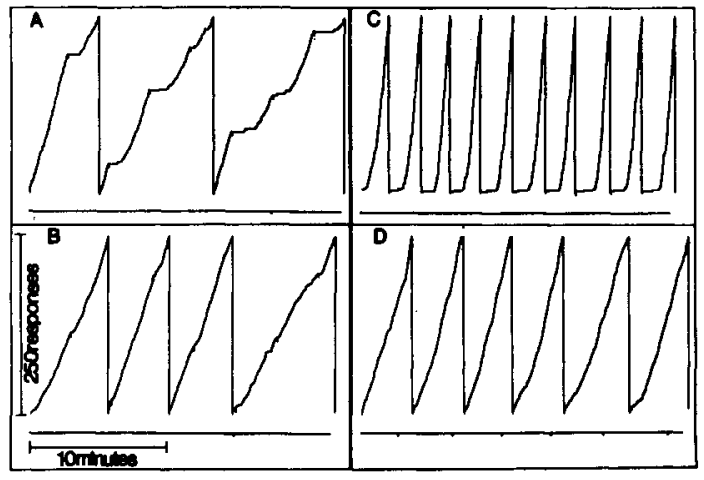

Fig. 1. Sample cumulative records showing fixed-interval performances under control (A) and under $4 \mathrm{mg} / \mathrm{kg}$ methylphenidate (B) conditions for $\mathrm{W} 3$ and fixed-ratio performances under control (C) and under $4 \mathrm{mg} / \mathrm{kg}$ methylphenidate (D) conditions for W2; the small downward strokes of the recording pen indicate 3 min time-out periods (CAS off, lever retracted) in which the paper feed stopped; short downward strokes of the event pen indicate shock deliveries. 

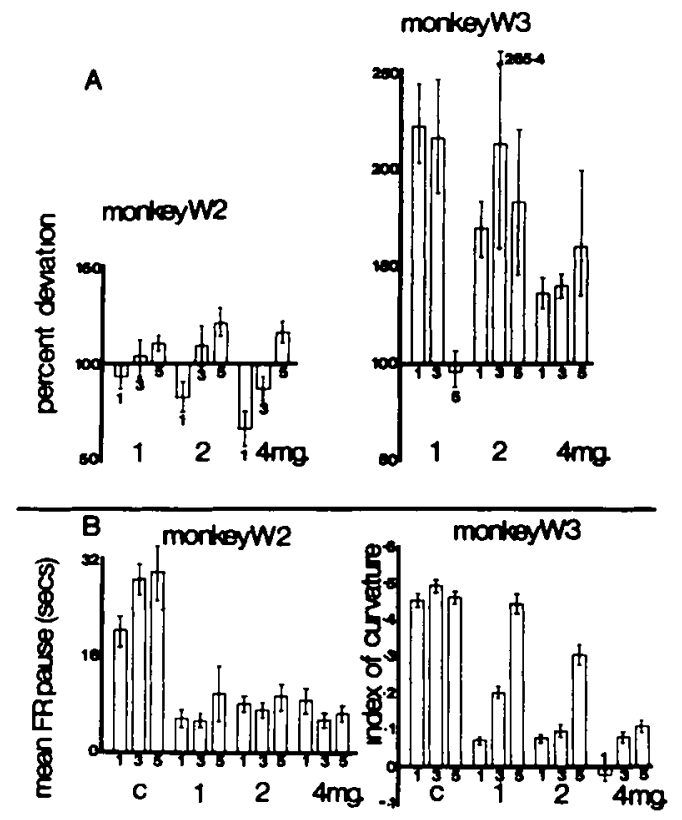

Fig. 2A. Shows average response rates per min at three dosages of methylphenidate (1 2 and $4 \mathrm{mg} / \mathrm{kg}$ ) for Monkey W2 (FR250) and Monkey W3 (FI 3 min) expressed as percentage deviation (rom respective control means $(=100 \%)$. Smaller numerals $(1,3,5)$ denote the first, third and fifth $45 \mathrm{~min}$ periods of a daily session; solid vertical lines denote the $\mathrm{SE}$ of the mean. Control data based on 10 sessions; drug data, five sessions in each case.

Fig. 2B. Shows, for Monkey W2, mean time (sec) before a response occurred after onset of CAS; control data $(C)$ and three dosages of methylphenidate $(1,2,4 \mathrm{mg} / \mathrm{kg})$ are shown for the first third and fifth 45 min periods of the session. For Monkey W3, average indices of curvature for $\mathrm{FI}$ performance are shown under control and drug conditions. Solid vertical lines refer to the $S E$ of the means. Control data based on 10 sessions; drug data, five sessions in each case.

produced substantial rate increases under FI 3, although the effect during the first $45 \mathrm{~min}$ after injection was inversely related, and during the last $45 \mathrm{~min}$ of the session, positively related to dosage.

Figure 2B shows the effects of methylphenidate on behavior for two further performance measures. First, the drug consistently reduced the pause immediately following the onset of CAS as compared with the control performance of W2 (FR 250). Second, calculation of the average index of curvature (Fry et al, 1960) for FI performance (W3) showed that methylphenidate modified the temporal patterning of responses characteristic of FI control performance. Confirmation of these trends may be found in the lower records of Fig. 1 which illustrate the effects of $4 \mathrm{mg} / \mathrm{kg}$ methylphenidate on $\mathrm{FI}(\mathrm{B})$ and FR (D) responding for W3 and W2, respectively.

Under control conditions, shocks occurred infrequently (W2, 1.06/45 $\mathrm{min} ; \mathrm{W} 3,1.46 / 45 \mathrm{~min})$; methylphenidate tended to increase shock frequency in both antmals as a function of increasing dosage: At $4 \mathrm{mg} / \mathrm{kg}$, W2 received 4.18 shocks $/ 45 \mathrm{~min}$ and $\mathrm{W} 3$ received 2.48 shocks $/ 45$ $\mathrm{min}$. However, the low overall frequency of shock suggests that termination of CAS constitutes the primary source of reinforcement in the present experiments.

Behavior maintained by termination of stimuli assoclated with aperiodic delivery of noxious stimulation was first reported by Dinsmoor (1962). Subsequent work (Azrin, Holz, \& Hake, 1962; Morse \& Kelleher, 1966) demonstrated the maintenance of patterns of responding characteristic of FR and FI schedules of food reinforcement but in which response rates were reinforced by termination of a "schedule complex" (Morse \& Kelleher, 1966) consisting of exteroceptive stimuli associated with brief electric shocks. Consequently, Morse and Kelleher suggested that the schedule of reinforcement may be a more important determinant of responding than the nature of the reinforcer used to control behavior. The present results appear to confirm and to extend the hypothesis since methylphenidate, a drug with behavioral effects similar to those of amphetamine, differentially affected responding in a manner consistent with the effects of these drugs on behavior controlled by different schedules of food reinforcement. The results are in close agreement with findings reported by Kelleher \& Morse (1964) for d-amphetamine in spite of some procedural differences and, in view of the extensive literature concerning the effects of drugs with central excitatory effects upon FI and FR schedules of positive reinforcement (e.g., Smith, 1964), the conclusion reached by Kelleher \& Morse (1964), that comparable schedules produce comparable drug-behavior dependencies when responding is maintained either by positive or by negative reinforcers, gains further support from the present observations.

\section{References}

Azrin, N. H., Holz, W. C., \& Hake, D. Intermittent reinforcement by removal of a conditioned aversive stimulus. Science, 1962, 136. $781-782$.

Dews, P. B. Studies on Behavior IV Stimulant actions of methamphetamine. J. Pharmacol. exp. Ther., 1958a, 122, 137-147.

Dews, P. B. Analysis of effects of psychopharmacological agents in behavioral terms. Federation Proc., 1958b, 17, $1024-1030$.

Dews, P. B., \& Morse, W. H. Behavioral pharmacology. Ann. Rev. Pharmacol., 1961, 1, 145-174.

Dinsmoor, J. A. Variable-interval escape from stimuli accompanied by shocks. J. exp. Anal. Behav., 1962, 5, 41-47.

Fry, W., Kelleher, R. T., \& Cook, L. A mathematical index of performance on fixed-interval schedules of reinforcement. $J$. exp. Anal. Behav., 1960, 3, 193-199.

Gollub, L. R., \& Brady, J. V. Behavioral pharmacology. Ann. Rev. Pharmacol., 1965, 5, 235-262.

Kelleher, R. T., \& Morse, W. H. Escape behavior and punished behavior. Federation Proc., 1964, 23, 808-817.

Morse, W. H., \& Kelleher, R. $\boldsymbol{T}$. Schedules using noxious stimuli: I Multiple fixed-ratio and fixed-interval termination of schedule complexes. J. exp. Anal. Behav., 1966, 9, 267-290.

Smith, C. B. Effects of d-amphetamine upon operant behavior of pigeons: enhancement by reserpine. J. Pharmacol. exp. Ther., $1964,146,167-174$.

\section{Note}

1. These investigations are supported by Grant No. APA-159 from the National Research Council of Canada. Thanks are due to Dr. C. W. Murphy of Ciba Ltd., Montreal, for making a supply of methylphenidate (Ritalin) available to us. 